\title{
Analysis on the Conduct of Managing Agent of State-owned Enterprises Based on Dual Reputation
}

\author{
Feng Kong ${ }^{1, a}$, Lin-Fang $\mathrm{He}^{2, \mathrm{~b}, *}$ \\ ${ }^{1,2}$ Department of Economics and Management, North China Electric Power University, Baoding, \\ China \\ a51913584@qq.com, bhelinfang@126.com \\ ${ }^{*}$ Corresponding author
}

\begin{abstract}
Keyword: State-owned enterprise, Agency by agreement, Dual reputation, The behavior of management.
\end{abstract}

\begin{abstract}
The state-owned enterprise managers have a great feature, the operator is appointed by the superior government, the operators' attention the relationship with administrative organization, the managers of state-owned enterprise have a strong consideration of reputation. The operator's retention and promotion depends on the operator's market reputation and political reputation. In the dual reputation, the operator behavior is divided into the normal behavior and the behavior of rent-seeking efforts, the operators maximize their expected utility through choosing their conduct. We analysis which factors influence the managers' behavior, and study how to stimulate normal effort, reduce the rent-seeking behavior.
\end{abstract}

\section{Introduction}

Principal-agent theory originated from "professional". The agent represent the client to act because of the relative advantage. The principal-agent theory is of vital importance to the reform of State-owned enterprise theoretically and practically. Between the operator and the government of China's state-owned enterprises have formed a principal-agent relationship, satisfy the information asymmetry, the contractual relationship, interest structure. Agency financially as a contractual relationship between the parties, there are obvious limits of responsibility, rights and benefit. Principal agent problem is information asymmetry, operator holds the information the client is unable to have[1]. The client should take appropriate incentives male agents commissioned to take the most expected action in maximizing their utility and utility agent can maximize the client.

Because of the information asymmetry, the behaviors of the operators are personal, here we study operator's two important behaviors: the normal behavior, the behavior of rent-seeking efforts. Normal effort behavior refers to in order to improve the performance of the business itself, the general managers pay. The behavior of rent-seeking is a short-term behavior, is decided by the characteristics of the dual identity of the state-owned enterprise manager in China, for the purpose of its political gains. Rent-seeking behavior and the performance of enterprises are independent. Selection and depute of the state-owned enterprise manager in China is directly determined by the competent department of the government[2]. The government department appoints the managers mainly refer to his political reputation. Government officials subjective will have a great influence on the operator's political reputation, the true response to his political reputation and not its business performance and ability[3]. How the government encourage the state-owned enterprise managers to improve enterprise performance, reduce the rent-seeking behavior, speculation, is a very practical significance and very important research area.

The incentive mechanism to the operator is generally divided into the economic incentive and reputation incentive. The managers of the state-owned enterprises in China have a strong reputation for consideration. In this paper, considering the reputation is double reputation, namely the market reputation and political reputation, feature selection operator behavior analysis under the condition of considering double reputation[4]. 


\section{The Behavior of Managers and Corporate Performance Model}

The article according to the different operator's efforts, we establish a corporate performance impact on the performance of different models.

Assuming that the performance of enterprises is a linear function of the manager's effort. Classification according to the behavior of managers, relationship between managers' behavior and current performance of the enterprise can be expressed as follows:

$$
\pi=\mathrm{a}_{1}+\theta
$$

In the formula, $\pi$ express enterprise performance, ${ }^{a_{1}}$ express the normal efforts that managers have to do to improve the performance, $\theta$ is a normal random variable which the mean value is 0 and the variance is $\delta^{2}$, We use it to express the interference of uncertain factors affecting corporate performance.[1]

The cost of manager's various behaviors is a kind of increasing marginal function, that means $c^{\prime \prime}\left(\mathrm{a}_{i}\right)>0$. The cost is generally set like this:

$$
c\left(\mathrm{a}_{i}\right)=\frac{1}{2} b_{i} a_{i}^{2}
$$

In the formula, $b_{i}$ is the cost coefficient of the the efforts of operators.

There is no correlation between various behaviors of managers, so we can assume that the cost function is like this:

$$
C\left(\mathrm{a}_{1}, \mathrm{a}_{2}\right)=\frac{1}{2} b_{1} a_{1}^{2}+\frac{1}{2} b_{2} a_{2}^{2}
$$

In the formula, $\mathrm{a}_{2}$ presents the rent-seeking behavior of manager.

\section{The Manager's Reputation Model}

Business reputation is one of the important elements of enterprise manager human capital. The reputation is the external expression of the enterprise executive ability and integrity. This paper combines the current situation of state-owned enterprise of our country, then put forward the double reputation model.

Reputation is often used as a intangible assets, which to some extent reflects the ability of the operator. The market reputation of manager refers to the market of enterprise performance evaluation of the enterprise to bring. When we assume the market risk does not exist, then the enterprise operator's performance to determine its market reputation. We can obtain the function of the market reputation:

$$
R_{m}=\mu \pi
$$

$\mu$ is the utility's coefficient of the market reputation.

Managers of China's State-owned enterprises as a business operator, but also have certain executive-level government officials. Compared with the market reputation, State-owned enterprise managers are more concerned about their own political reputations. Manager's political reputation under the influence of subjective evaluation staff. Therefore prone to operator of rent-seeking 
behavior. On the premise of rent-seeking success, political reputations is a linear function on the rent-seeking behavior of increasing probability of success, the function of political reputation is like this:

$$
R_{0}=p h a_{2}-(1-p) \mathrm{rha}_{2}
$$

In the upper formula, $p$ represents the possibility of that the manager successfully to do rent-seeking. $h$ expresses utility's coefficient of manager's reputation which his rent-seeking behavior brings to him. $r$ is the strength of punishment bring to manager from the supervision department, when the rent-seeking behavior has been found.

There are two parts of the market reputation and political reputation, according to expected utility theory, utility is additive. Therefore, the reputation of the expected utility operators can be expressed as:

$$
R=\lambda R_{m}+(1-\lambda) \mathrm{R}_{0}
$$

In the upper formula, $\lambda$ is the influence coefficient of $R_{m}$ does to reputation, $1-\lambda_{\text {is influence }}$ coefficient of $R_{0}$ does to reputation, the value of $\lambda$ decided by the government, usually $0 \leq \lambda \leq 1[5]$.

\section{Manager's Wages Model}

Manager's wages consist of fixed salary and incentive pay, and wages contract of enterprise for operators can be like this:

$$
S_{0}=s+\beta \pi
$$

$S$ is the fixed salary, and $\beta$ is the coefficient of manager's performance royalty.

The utility maximization of manager is:

$$
\begin{aligned}
& \max E_{1}=S_{0}+R-C\left(\mathrm{a}_{1}, \mathrm{a}_{2}\right) \\
& =s_{0}+\beta \mathrm{a}_{1}+\lambda \mu a_{1}+(1-\lambda)\left[\mathrm{pha}_{2}-(1-\mathrm{p}) \mathrm{rha}_{2}\right]-\frac{1}{2} b_{1} a_{1}^{2}-\frac{1}{2} b_{2} a_{2}^{2}
\end{aligned}
$$

In the case of asymmetric information, the agent chooses the optimal level of effort for each behavior to maximize their income to determine the equivalence, the first-order conditions are:

$$
\begin{aligned}
& \frac{\partial\left(\mathrm{E}_{1}\right)}{\partial a_{1}}=\beta+\lambda \mu-b_{1} a_{1}=0 \\
& \frac{\partial\left(\mathrm{E}_{1}\right)}{\partial a_{2}}=(1-\lambda)[\mathrm{ph}-(1-\mathrm{p}) \mathrm{rh}]-\mathrm{b}_{2} a_{2}=0
\end{aligned}
$$

According to the above 2 equations to obtain the optimal effort level, we can know: 


$$
a_{1}=\frac{\beta+\lambda \mu}{b_{1}}>0 \quad a_{2}=\frac{(1-\lambda) \mathrm{h}[\mathrm{p}-(1-\mathrm{p}) \mathrm{r}]}{b_{2}}>0
$$

\section{The assessment model}

Operator's political reputation is derived from the assessment, assessment of state-owned enterprises belong to the internal assessment, which is the cause of the operator of rent-seeking behavior.

In the absence of supervision, assessment and management carry out the game:

Tab. 1 assessment and management carry out the game without supervision

\begin{tabular}{|c|c|c|}
\hline & Rent-seeking & Not rent-seeking \\
\hline Accept & $h a_{2}-\frac{1}{2} b_{2} a_{2}^{2}, a_{2}$ & 0,0 \\
\hline Not Accept & 0,0 & 0,0 \\
\hline
\end{tabular}

$h a_{2}-\frac{1}{2} b_{2} a_{2}^{2}>0$

. According to the upper table, (Rent-seeking, Accept) is the Nash Equilibrium of managers and assessment. In this evaluation system, operators and evaluation are inevitable conspiracy.

Under supervised conditions, assessment and management carry out the game:

Tab. 2 assessment and management carry out the game under supervised conditions

\begin{tabular}{|c|c|c|}
\hline & Rent-seeking & Not rent-seeking \\
\hline Accept & $R_{0}-\frac{1}{2} b_{2} a_{2}^{2}, a_{2}$ & 0,0 \\
\hline Not Accept & 0,0 & 0,0 \\
\hline
\end{tabular}

If $R_{0}-\frac{1}{2} b_{2} a_{2}^{2}<0$, (Rent-seeking, Accept) is not the Nash Equilibrium. Operators and people would not conspiracy. If $R_{0}-\frac{1}{2} b_{2} a_{2}^{2}<0$, then $p h a_{2}-(1-p) \operatorname{rha}_{2}-\frac{1}{2} b_{2} a_{2}^{2}<0$, so we get that $r>\frac{p h-\frac{1}{2} b_{2} a_{2}}{(1-\mathrm{p}) \mathrm{h}}$. According to that, we can conclude that as long as the punishment to a certain extent, we can avoid those operators and assessment conspiracy.

\section{Summary}

By analyzing the behavior of operators based on the dual reputation, we drawn that the manager's normal efforts is not 0 . The operator of state-owned enterprise income consists of two parts, salary and reputation income structure. Behavior normal effort cost coefficient $b_{1}$ and the normal behavior of the operators strive negative correlation relationship, the higher the cost of normal behavior efforts, the efforts of the operators to pay less. The relationship between normal behavior efforts with the performance royalty coefficient $\beta$ is positively related, the relationship between the influence coefficient of $R_{m}$ does to reputation $\lambda$ and the utility's coefficient of the market reputation $\mu$ just is the same. The government wants to improve the performance of state-owned enterprises have to enhance the operator's normal efforts, to improve the performance royalty coefficient, market reputation utility coefficient, the influence coefficient of $R_{m}$ does to reputation 
$\lambda$, that can be increased to normal efforts. In terms of the government's operation, improve the normal effort and performance royalty coefficient $\beta$ more easily.

Rent-seeking behavior of manager is also greater than 0 . The cost coefficient of rent-seeking behavior $b_{2}$ and rent-seeking behavior of managers are negatively correlated, the higher the cost of rent-seeking behavior, this effort of manager is smaller, rent-seeking behavior is less. The punishment of the regulatory authorities and the rent-seeking behavior are negatively correlated, the punishment is greater, the less the rent-seeking behavior. If the government wants to make of rent-seeking behavior becomes less, it must control the success of rent-seeking behavior, or to increase the punishment of rent-seeking behavior.

\section{References}

[1] Weiyin Zhang. Game Theory and Information Economics [M]. Shanghai: Shanghai People's Publishing House, 1996.

[2] Feng Kong, Guoping Song. Analysis of state-owned manager's game contract of dual reputation under equity incentive [J]. Business Studies, 2011(8):112-117.

[3] Tadelis S. The market for reputations as an incentive mechanism. The Journal of Political Economy. 2002.

[4] Hemang Desai,Chris E Hogan,Michael S.Wilkins. The Reputational Penalty for Aggressive Accounting: Earnings Restatements and Management Turnover. The Accounting Review. 2006.

[5] Hongyan Liu, Feng Kong. Research on the incentive of managers of state owned enterprises in China [M]. Beijing: China Agricultural Science and Technology Press 2009:66-71. 